\title{
Serial Changes in Image Findings of Herniation Pits from the First Appearance
}

\author{
Hee Joong Kim, MD, Seung Won Jeon, MD, Hanbual Yang, MD, Sun Hyung Lee, MD, Jeong Joong Yoo, MD \\ Department of Orthopedic Surgery, Seoul National University Hospital, Seoul, Korea
}

Background: Herniation pits (HPs) have been considered to be an incidental finding, but recently femoroacetabular impingement (FAl) has been proposed as a possible cause of their formation. The findings on bone scans of HPs are variable in the literature: some showed increased uptake; the majority did not. We hypothesized that serial changes in image findings of HPs would explain the reason for the variable bone scan findings.

Methods: Four patients ( 5 hips) were followed up for more than 7 years. All patients were women and regularly underwent bone scintigraphy after the diagnosis of breast cancer. Small lesions with increased uptake were first detected on bone scintigraphy at the age of 44 to 64 years. In all cases, the lesions were confirmed by magnetic resonance imaging and follow-up bone scintigrams were taken regularly. Four lesions were also evaluated by computed tomography. Changes in the size of the pits and the intensity of the increased uptake on bone scintigraphy were evaluated.

Results: On the bone scintigrams, the lesions with increased uptake were detected in the femoral neck at 5-20 months after previous negative bone scintigraphy. There had been no events or symptoms associated with the newly detected increased uptake. On follow-up scans, the intensity of the uptake decreased gradually and the areas of increased uptake disappeared completely at 14-50 months after their first appearance. In 3 cases (2 patients), the pit size increased during follow-up.

Conclusions: The areas of increased uptake on bone scintigraphy gradually disappeared in all cases and the increase in pit size was frequent. There was no case in which signs or symptoms suggestive of FAl were noticed.

Keywords: Herniation pit, Bone scintigram, Uptake change, Size change

Herniation pits (HPs) refer to small, round to oval subcortical radiolucency with a thin sclerotic margin, located typically in the proximal anterosuperior quadrant of the femoral neck. Pitt et al. ${ }^{1)}$ first proposed the term herniation pit to describe this fibrocystic lesion, which has been considered to be the result of mechanical stress from the anterior joint capsule and overlying anterior muscles. The lesion has usually been recognized as incidental and benign, ${ }^{1-6)}$ but recently several reports have suggested that femoroacetabular impingement (FAI) could be the pos-

Received February 3, 2020; Accepted February 19, 2020

Correspondence to: Hee Joong Kim, MD

Department of Orthopedic Surgery, Seoul National University Hospital, 101 Daehak-ro, Jongno-gu, Seoul 03080, Korea

Tel: +82-2-2072-2970, Fax: +82-2-764-2718

E-mail: oskim@snu.ac.kr sible cause of the appearance of an $\mathrm{HP}^{7-13)}$

Image findings of HPs are well described in most published reports, but the findings on bone scintigrams are variable: some demonstrated increased uptake and some did not. ${ }^{1,2,4,6-8,14)}$ Some reports included time-dependent changes in the image findings, ${ }^{4,6,711)}$ but no reports described the time point at which the images were taken after the first development of an HP. In this study, we evaluated long-term serial changes in image findings of HPs from the first appearance.

\section{METHODS}

We conducted this study in compliance with the principles of the Declaration of Helsinki. This retrospective case-series study was approved by the Institutional Review Board (IRB No. H-1608-166-788). The requirement for informed 
Kim et al. Serial Changes in Image Findings of Herniation Pits

Clinics in Orthopedic Surgery • Vol. 12, No. 3, $2020 \bullet$ www.ecios.org

consent was waived.

Four women (5 hips) were included in the study. All patients underwent follow-up bone scintigraphy biannually or annually after diagnosis of breast cancer (Table 1). The increased uptake in the femoral neck was first detected between July 2006 and December 2008 when the patients were between 44 and 64 years of age. In all cases, no increased uptake was detected in the femoral neck on the initial bone scintigram. In all cases, the lesions were confirmed on simple radiographs and magnetic resonance (MR) images. After detection, image findings of the lesions were followed up for 7.5-10 years, mainly by using bone scintigraphy and plain radiography. In 4 cases (3 patients), computed tomographic (CT) images were taken and in 3 cases (2 patients), follow-up CT images were available. On plain radiographs, the $\alpha$ angle and center-edge (CE) angle

Table 1. Changes in the Intensity of Increased Uptake and Size of Herniation Pits

\begin{tabular}{|c|c|c|c|c|c|c|c|}
\hline \multirow{2}{*}{ Patient } & \multirow{2}{*}{ Case $^{*}$} & \multicolumn{4}{|c|}{ Bone scintigram } & \multicolumn{2}{|c|}{ Size $\left(\mathrm{mm}^{2}\right)$} \\
\hline & & Initial & Increased uptake detected & Increased uptake disappeared & Last & Initial & Last \\
\hline \multirow[t]{2}{*}{ I } & $1(\mathrm{R}) 63$ & 2002-01-04 & 2006-07-13 (6th) & 2009-09-17 (9th) & 2016-08-04 & $10 \times 13$ & $21 \times 18$ \\
\hline & 2 (L) 64 & & 2007-07-26 (7th) & 2009-09-17 (9th) & & $7 \times 11$ & $19 \times 24$ \\
\hline$\|$ & 3 (L) 60 & 2005-09-14 & 2006-12-12 (4th) & 2011-01-07 (12th) & $2017-11-27$ & $8 \times 9$ & No change \\
\hline III & 4 (L) 44 & $2006-08-28$ & 2007-07-19 (2nd) & 2009-06-11 (4th) & $2014-12-23$ & $9 \times 9$ & $11 \times 14$ \\
\hline IV & $5(\mathrm{~L}) 46$ & 2007-06-02 & $2008-12-29$ (4th) & 2010-02-10 (7th) & 2017-06-20 & $5 \times 4$ & NA \\
\hline
\end{tabular}

NA: not available.

*Values are presented as number (side) age (yr). Age at which the increased uptake was detected initially.
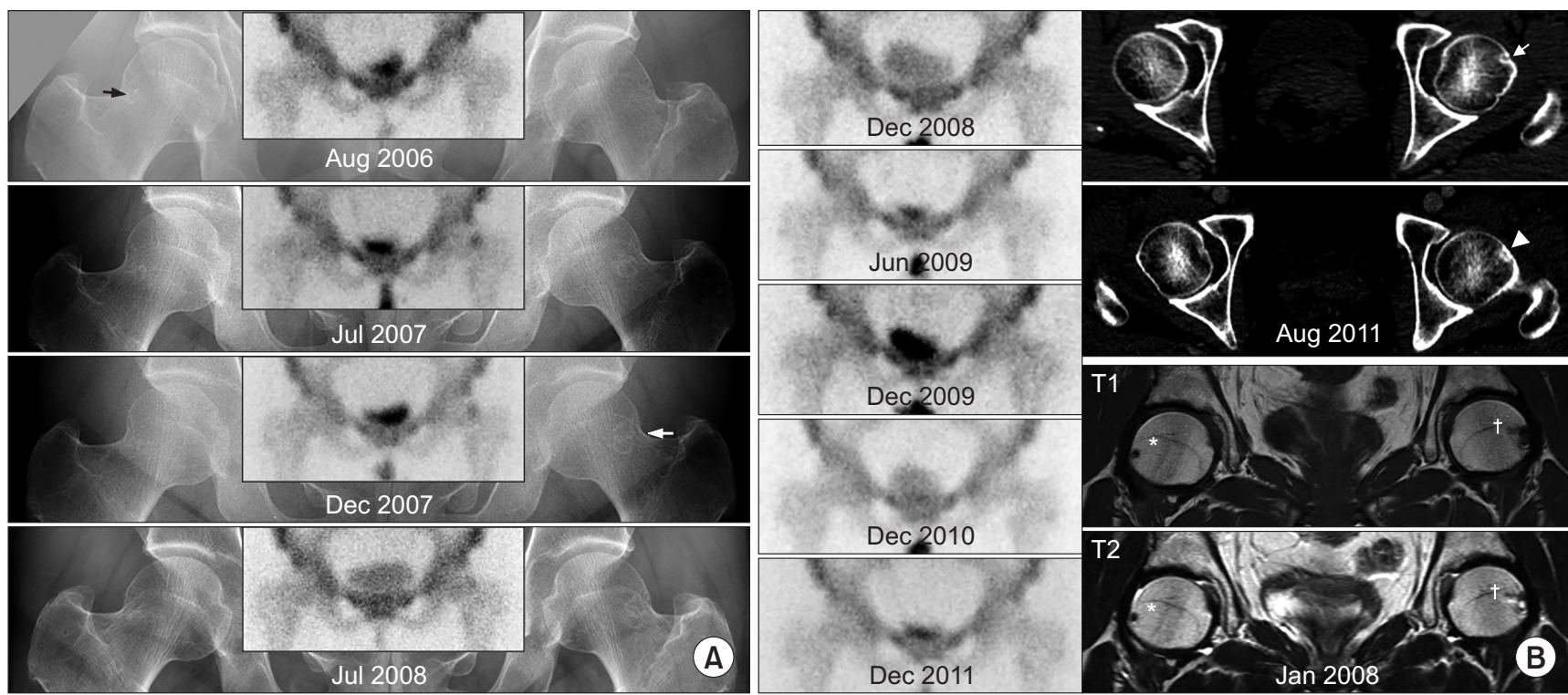

Fig. 1. Image findings of a herniation pit in a 43-year-old woman. (A) No increased uptake was identified on the first bone scan taken in August 2006. There was a preexisting herniation pit (black arrow) in the right hip on the plain radiograph. However, there was no increased uptake in the right hip. Approximately 1 year later, the increased uptake area was detected in the left hip on the bone scan and an oval lucent lesion with sclerotic margin was observed in the upper lateral quadrant of the left femoral neck. The size of the left herniation pit increased (white arrow) on the follow-up radiograph and the intensity of the uptake decreased gradually. (B) The increased uptake in the left hip disappeared completely approximately 2 years after first appearance (June 2009). An opening hole (arrow) and a septum (arrowhead) were identified in the herniation pit on computed tomographic images. On magnetic resonance images taken 6 months after the first detection of the increased uptake in the left hip, the interior of the herniation pit demonstrated low signal intensity on T1-weighted image and high signal intensity on T2-weighted image (dagger). The signal intensity of the interior part of the preexisting right herniation pit was low on both T1- and T2-weighted images (asterisk). 
Kim et al. Serial Changes in Image Findings of Herniation Pits

Clinics in Orthopedic Surgery • Vol. 12, No. 3, 2020 • www.ecios.org

were measured. $^{15,16)}$ On follow-up images, changes in the lesion size and intensity of the increase in uptake on bone scintigraphy were evaluated.

\section{RESULTS}

On the bone scintigram, increased uptake in the femoral neck was detected at 5-20 months after the previous negative bone scintigram. There was no event or symptom associated with the newly detected increased uptake. On the follow-up scans, the intensity of the increased uptake decreased gradually and the areas of increased uptake disappeared completely at 14-50 months after their first appearance (Figs. 1 and 2A).

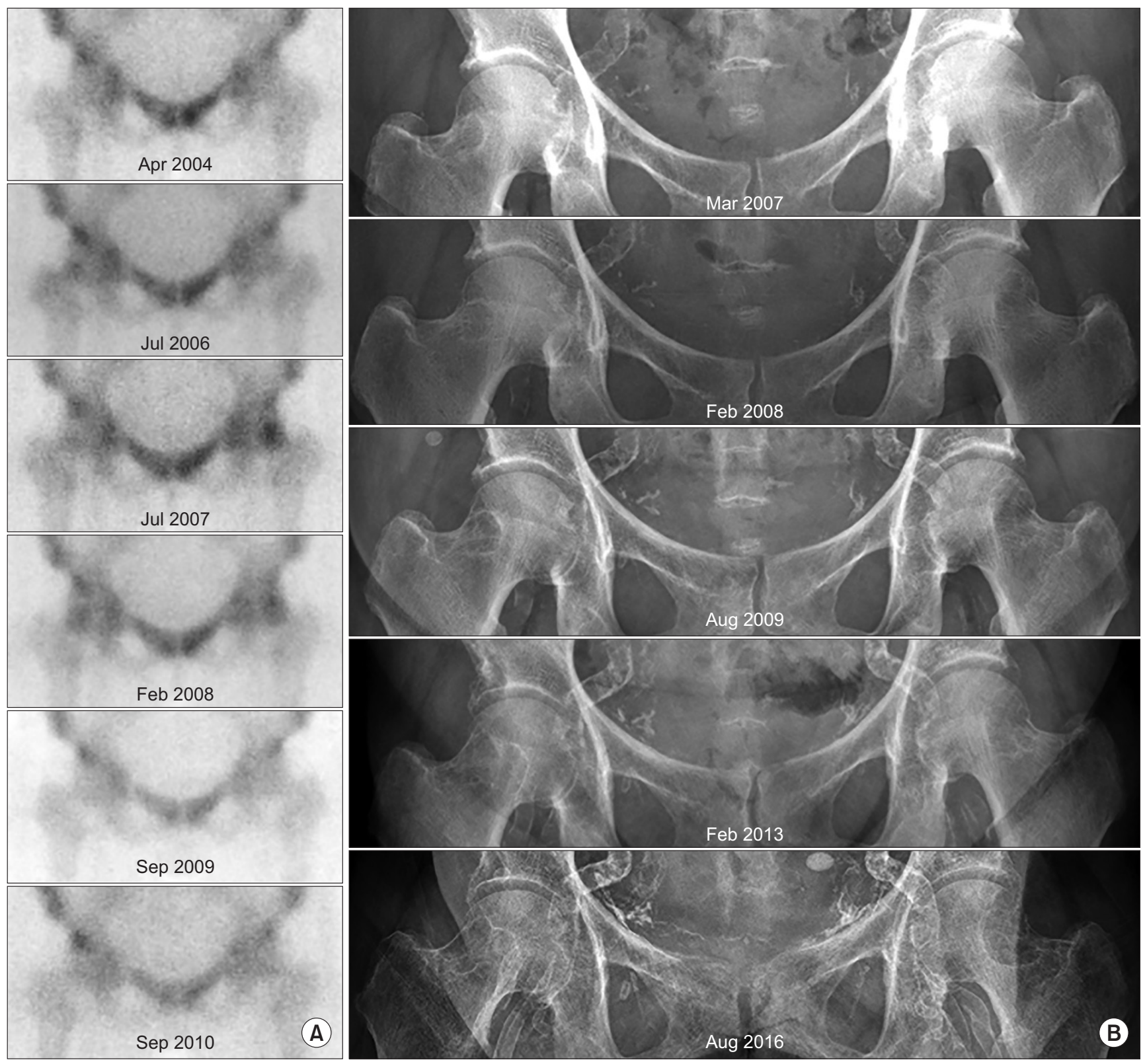

Fig. 2. Image findings of a herniation pit in a 59-year-old woman. (A) Increased uptake was detected in the right hip in July 2006 and in the left hip in July 2007. The intensity of increase in uptake decreased gradually in both hips and the areas of uptake disappeared completely in September 2009. (B) A gradual increase in the size of both herniation pits was observed. (C) On computed tomographic images, an opening hole (arrow), septation (arrowhead), and flattening of the outer wall (asterisk) were observed. (D) On magnetic resonance images, the interior part of both herniation pits demonstrated low signal intensity on T1-weighted images and high signal intensity on T2-weighted images. Bone marrow edema pattern (arrow) was observed around the newly developed herniation pit in the left hip. (Continued) 
Kim et al. Serial Changes in Image Findings of Herniation Pits

Clinics in Orthopedic Surgery • Vol. 12, No. 3, $2020 \bullet$ www.ecios.org

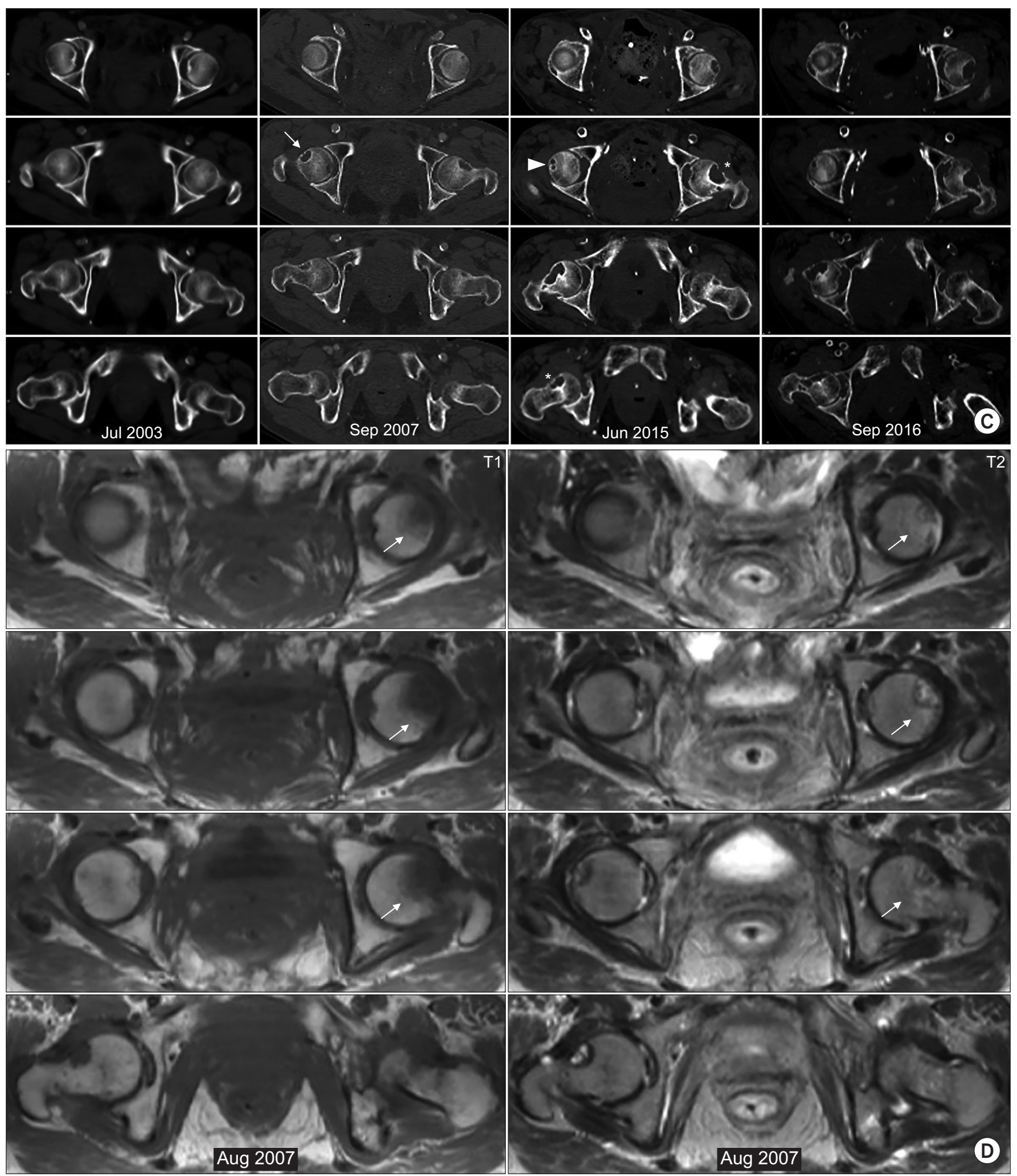

Fig. 2. Continued.

Radiolucency with faint sclerotic margin was observed in the superolateral aspect of the femoral neck on the plain radiographs taken approximately at the time when the increased uptake at the corresponding area was first noticed. In 3 patients, previous plain radiographs were available. In 1 patient, a preexisting HP was detected 
Kim et al. Serial Changes in Image Findings of Herniation Pits

Clinics in Orthopedic Surgery • Vol. 12, No. 3, $2020 \bullet$ www.ecios.org

on the right hip (Fig. 1A) and no cystic lesion was detected in the remaining 5 hips. The measured $\alpha$ angles were $34^{\circ}-39^{\circ}$ and $36^{\circ}-40^{\circ}$ for the right and left hips, respectively. The measured CE angles were $32^{\circ}-44^{\circ}$ and $36^{\circ}-45^{\circ}$ for the right and left hips, respectively. The initial pit size ranged between $5 \times 4 \mathrm{~mm}^{2}$ and $10 \times 13 \mathrm{~mm}^{2}$. In 3 cases $(2$ patients), the pit size increased on follow-up (Figs. 1A and 2B) and in 1 patient, the right lesion was measured as $21 \times$ $18 \mathrm{~mm}^{2}$ and the left lesion was measured as $19 \times 24 \mathrm{~mm}^{2}$ at the last follow-up (Fig. 2B). No fracture occurred in any lesions (even in the 2 large ones) and no patient had symptoms or signs suggestive of FAI throughout the follow-up period.

On the CT images, there was a small opening in the overlying anterior cortex in 4 cases and an internal septum in 2 cases (Figs. 1B and 2C). In 2 large lesions, flattening of the overlying anterior cortex was observed (Fig. 2C).

In all cases, the interior part of the pit exhibited low signal intensity on T1-weighted MR images and high signal intensity on T2 weighted images. However, in the case of the old lesion in 1 patient, the interior area of the lesion exhibited low signal intensity on both T1- and T2-weighted images (Fig. 1B). In 1 case, the HP was accompanied by surrounding bone marrow edema (Fig. 2D).

\section{DISCUSSION}

The HP has been reported to be the most common finding among lesions with asymptomatic abnormal femoral neck focal uptake on bone scintigraphy. ${ }^{14)}$ It is a benign and usually asymptomatic lesion, but it may raise concern in the evaluation for metastasis. ${ }^{2,17)}$ In previous reports, HPs did not show an increase in uptake in many cases. ${ }^{1,6,8}$ The results of the current study explain the reason for the appearance of different findings on bone scintigraphs. In the current study, the increased radioisotope uptake was observed in all cases at the time of the early stage of the appearance of HPs. Subsequently, the uptake decreased gradually and disappeared in approximately 1-4 years. None of the cases was symptomatic even in the period of increased uptake.

There have been reports demonstrating an increase in the size of HPs detected during radiographic followup performed $0.5-6$ years later. ${ }^{4,6,7)}$ The risk of fracture through a large HP might be a matter of concern. ${ }^{1)}$ The size increase was observed in 3 cases ( 2 patients) in our study. In 1 case, there was a small increase in the first 5 months. In the other 2 cases ( 1 patient), the lesions enlarged gradually for 8 years and 9 years, and were measured as $21 \times 18 \mathrm{~mm}^{2}$ and $19 \times 24 \mathrm{~mm}^{2}$. However, there was no occurrence of fracture until the last follow-up when the patient was 73.5 years old. Even though no reports of a pathologic fracture through the large HP were found during our literature search, it might be necessary to follow-up closely enlarging HPs.

Pitt et al. ${ }^{1)}$ observed a perforation or defect in the anterior overlying cortex of the subcortical pit or cavity in gross and histological examinations and suggested the name herniation pit. CT images revealed the frequent presence of small cortical perforation in the anterior cortex of the pits. ${ }^{4,67}$ In the current study, focal cortical perforation was observed in all cases that were examined with CT, and fragmentation of the anterior thin cortex was observed in 2 cases with large-sized HPs.

Daenen et al. ${ }^{7)}$ observed a surrounding bone marrow edema pattern in 1 of 3 symptomatic HPs. In our study, 1 pit demonstrated surrounding bone marrow edema pattern (Fig. 2D). The pit was large in size and the MR images were taken relatively early after initial detection, but there was no report of pain or discomfort.

In our study, the $\alpha$ and lateral CE angles were not suggestive of the bump in the femoral neck or acetabular overcoverage. In addition, no case showed any findings suggestive of FAI, such as the crossover sign, posterior wall sign, or ischial spine sign. FAI brings about impact force on the impingement site in addition to the pressure from the anterior capsule and overlying muscles. Therefore, a higher incidence of HPs might be expected in patients with FAI. Nevertheless, the results of this study indicate that the HP should not be misunderstood as a sign suggesting the high probability of FAI, as opposed to some other studies. ${ }^{14,18,19)}$

The limitation to be pointed out in this study is the small number of cases. However, the serial changes in bone scan findings were very consistent in all cases. All HPs showed increased uptake on bone scintigram when they first appeared. Then, the areas of increased uptake decreased gradually and disappeared completely in a few years.

\section{CONFLICT OF INTEREST}

No potential conflict of interest relevant to this article was reported.

\section{ACKNOWLEDGEMENTS}

This study was supported by a grant (06-03-0630) from the Seoul National University Hospital Research Fund. 
Kim et al. Serial Changes in Image Findings of Herniation Pits

Clinics in Orthopedic Surgery • Vol. 12, No. 3, $2020 \bullet$ www.ecios.org

\section{REFERENCES}

1. Pitt MJ, Graham AR, Shipman JH, Birkby W. Herniation pit of the femoral neck. AJR Am J Roentgenol. 1982;138(6): 1115-21.

2. Thomason CB, Silverman ED, Walter RD, Olshaker R. Focal bone tracer uptake associated with a herniation pit of the femoral neck. Clin Nucl Med. 1983;8(7):304-5.

3. Nokes SR, Vogler JB, Spritzer CE, Martinez S, Herfkens RJ. Herniation pits of the femoral neck: appearance at MR imaging. Radiology. 1989;172(1):231-4.

4. Crabbe JP, Martel W, Matthews LS. Rapid growth of femoral herniation pit. AJR Am J Roentgenol. 1992;159(5):1038-40.

5. Polger M, Aliabadi P. Radiologic vignette: the radiographic findings are typical of herniation pit of the femoral neck. Arthritis Rheum. 1993;36(4):572-4.

6. Gao ZH, Yin JQ, Ma L, Wang J, Meng QF. Clinical imaging characteristics of herniation pits of the femoral neck. Orthop Surg. 2009;1(3):189-95.

7. Daenen B, Preidler KW, Padmanabhan S, et al. Symptomatic herniation pits of the femoral neck: anatomic and clinical study. AJR Am J Roentgenol. 1997;168(1):149-53.

8. Borody C. Symptomatic herniation pit of the femoral neck: a case report. J Manipulative Physiol Ther. 2005;28(6):44951.

9. Leunig M, Beck M, Kalhor M, Kim YJ, Werlen S, Ganz R. Fibrocystic changes at anterosuperior femoral neck: prevalence in hips with femoroacetabular impingement. Radiology. 2005;236(1):237-46.

10. Beall DP, Sweet CF, Martin HD, et al. Imaging findings of femoroacetabular impingement syndrome. Skeletal Radiol. 2005;34(11):691-701.

11. Gunther KP, Hartmann A, Aikele P, Aust D, Ziegler J. Large femoral-neck cysts in association with femoroacetabular impingement: a report of three cases. J Bone Joint Surg Am. 2007;89(4):863-70.

12. Kavanagh EC, Read P, Carty F, Zoga AC, Parvizi J, Morrison WB. Three-dimensional magnetic resonance imaging analysis of hip morphology in the assessment of femoral acetabular impingement. Clin Radiol. 2011;66(8):742-7.

13. Scheyerer MJ, Copeland CE, Stromberg J, Ruckstuhl T, Werner CM. Radiographic markers of femoroacetabular impingement: correlation of herniation pit and femoral bump with a positive cross-over ratio. Adv Orthop. 2014;2014: 432728.

14. Sopov V, Fuchs D, Bar-Meir E, Gorenberg M, Groshar D. Clinical spectrum of asymptomatic femoral neck abnormal uptake on bone scintigraphy. J Nucl Med. 2002;43(4):484-6.

15. Notzli HP, Wyss TF, Stoecklin CH, Schmid MR, Treiber K, Hodler J. The contour of the femoral head-neck junction as a predictor for the risk of anterior impingement. J Bone Joint Surg Br. 2002;84(4):556-60.

16. Wiberg G. The anatomy and roentgenographic appearance of a normal hip joint. Acta Chir Scand. 1939;83(Suppl 58):738.

17. Yoo SW, Song HC, Oh JR, et al. Herniation pit mimicking osseous metastasis on 18F-FDG PET/CT in patient with lung cancer. Clin Nucl Med. 2012;37(7):682-3.

18. Lee E, Choi JA. Associations between alpha angle and herniation pit on MRI revisited in 185 asymptomatic hip joints. Korean J Radiol. 2015;16(6):1319-25.

19. Mimura T, Mori K, Itakura S, Furuya Y, Kawasaki T, Imai S. Prevalence of pincer, cam, and combined deformities in Japanese hip joints evaluated with the Japanese Hip Society diagnostic guideline for femoroacetabular impingement: a CT-based study. J Orthop Sci. 2017;22(1):105-11. 